\title{
The Application of Transitional Devices in English Writing Teaching
}

\author{
Tong Lili ${ }^{1}$ \\ ${ }^{1}$ School of Foreign Languages, Dalian Jiaotong University, Dalian, Liaoning 116028, China \\ Email: Elizabeth_1998@163.com
}

\begin{abstract}
Writing a logical article is influenced by many factors, among which transitional devices play a vital role. As modern English grammar expands the grammar research field from lexical and syntactic study to the study of article structure, it requires the development of paragraph and articles be logical in structure and coherent in meaning. To achieve this goal, it is not enough to combine some complicated sentences and words in English. So, how to make a paragraph or a sentence naturally transit to another arouses many researchers' attention. The use of transitional words makes the text well-organized. Since English are different from Chine in structure, it is necessary to arouse Chinese students' awareness in understanding and using of transitional words in writing. This paper is to study the definition, classification and application of the transitions in English writing teaching.
\end{abstract}

\section{Keywords: Transitional devices, Classification, Application, English Writing Teaching}

\section{INTRODUCTION}

One of the writing criteria is coherence. Transitional devices play an essential role in achieving coherence in English writing. Therefore, how to make good use of the transitional words and phrases becomes one of the focuses in English writing classes. Due to the fact that some Chinese students haven't realized the essential role the transitional devices play in an English writing, their writing may not be coherent, and are often full of run-on sentences, or confusing in meaning. To solve this problem, many techniques can be employed, one of which is to skilfully make good use of transitional words and phrases, which serve as bridges in linking both the meaning and structure together logically. The basic function of transitional words and phrases is to build a bridge between the meaning of the sentences or the paragraphs.

It is necessary for teachers to arouse the students' awareness in structural difference between Chinese and English. It is said that English is hypotactic, having a feature of "dependent or subordinate construction or relationship of clauses with connectives". However, Chinese tends to be paratactic, and usually considered as "the arranging of clauses one after another without connectives showing the relation between them". The striking difference makes it essential for Chinese students to pay more attention to the structural characteristics in English writing. With the transitional words and phrases they have mastered, they can make their writing more coherent and logical.

\subsection{The Definition of Transitions}

Transitions are words or phrases that show the relationship between sentences or paragraphs of a text or sections of a speech. In building up the relationship between different sections, one of the important methods is to apply the transitional words or phrases. The transitional words also can be called the logical link of the text structure, which can strengthen the article's logical relationship. Moreover, they make the structure more rigorous and more coherent. In addition, synonyms and the repetition of words can play a role as transitions in English.

\subsection{The Study of Transitions}

Traditional grammar mainly focused on morphology and syntax and did not relate to the structure of the article. Modern English grammar expands the grammar study from morphology and syntax to paragraphs and the whole discourse structures. It also combines the research of morphology and syntax with their application in articles, and combines grammar description with specific communicative situations and 
language environment. These combinations lead to problems in our language application process.

The development of paragraph and the composition of article need be consistent with the logical sequence and with cohesive meaning. In order to achieve this goal, it is not sufficient to only piece a few English sentences together. Instead, the proper use of English transitional words may be helpful for students to approach this goal in writing. Learning the classification of it makes an essential part in the writing practice.

The transitional words are not only the means of linking sentences, but also the way to represent the relationships between sentences or paragraphs.

\section{CLASSIFICATION}

Transitions can be divided into different categories. According to Zhang Zhenbang's classification, there are three types: logical connector, grammar connector and lexical connector. And R - Quirk categorized them into 13 kinds. These researchers mainly classify the words by function in connecting sentences and paragraphs.

The transitional words include some conjunctions, adverbs and prepositional phrases which represent the examples, the turning point, cause and effect, etc. In English, there are a lot of phrases which function as a link between different sections besides the transitional words. The transitional words have already gone beyond the scope of lexical classification, and extend to the syntactic category. They are not only connections of sentences, but show the logical relationships among sentences and do help to make the sentences, paragraphs and passages complete and logical. This paper is gonging to focus on the classification of transitions from two aspects, meaning and logical structure.

\subsection{Meaning}

Each transition has its own meaning, so they belong to a variety of functional categories. Some words and expressions represent time sequence, such as "to start with", "then", and "in the end". Some indicate contrast and comparison like "in spite of", and "although". And the words mean reason, such as "because of", "now that", and "since". Also the expressions like "as a result" and "therefore" show the consequence. Apart from the above, some other words and expressions can be used to indicate illustration, coordinating relationships, adversative relationships, progressive relationships, statement of facts, purpose, emphasis, summary, etc.

\subsection{Logical Structure}

The relationships between sentences or paragraphs are not only expressed by meaning, but also from logical structure aspect. In writing a paragraph or an article, logical structures are often expressed by transitional words and expressions.

In a typical English essay, there are usually three parts, introduction, body and conclusion. Introduction serves as the opening part of the essay. It introduces the main topic and thesis statement of writing. The transitional words introducing the topic often appear at the beginning of the paragraph, such as "nowadays", "as we all know", and "When it comes to".

In the body part, the writer usually organizes the writing according to certain logical orders. Sometimes causes or effects are analysed; sometimes a comparison or contrast is made. For instance, when the writer wants to make a list of the reasons, a series of transitions will be employed, such as "first", "second" and "finally".

In the conclusion part, the expressions representing a summary like "in short", "generally speaking", "all in all" might be good choices to start the conclusion part.

\section{DIFFERENT FORMS OF TRANSITIONS}

English transitions are in different forms. They are mainly adverbs, prepositions, conjunctions, prepositional phrases, verbal infinitive phrases, pronouns, and noun phrases etc. They can be placed at the beginning of a sentence, in the middle of a sentence, or at the end of a sentence. But not all the transitions can appear in all the above places.

--Many people want to lose weight by exercising. They eat too much. They way might not be very effective.

--Many people want to lose weight by exercising every day. However, if they eat too much, the way might not be very effective

The first paragraph seems confusing and the logical relationship of the three sentences is not very clear. But after revision, the second paragraph appears to be more coherent.

In addition, synonyms can also function as transitional words. The repetition of the English words can also play a role as the transitional words. However, the simple repetition may sometimes sound boring. Moreover, in the passage, when one paragraph transits to another paragraph, sometimes they do not need any transitional words or phrases, but rely on a rhetorical question. This kind of rhetorical question can also act as transitions.

English paragraphs and articles are sometimes organized according to various sequences or logical structures, such as time sequence, space order, the order of importance. In a different order, the use of transitional words may be different. Even in the same order, the choice of words can also be another story. 
Transitional words and phrases are widely used in all kinds of writings, for they are large in number and their functions are diverse.

\section{APPLICATION IN WRITING}

Making the transitional words and phrases recognized is only the first step, what the teachers really need to do is to lead the students to apply them in the writing process. Actually, rote learning is not a wise choice. To read to write is recommended in English writing teaching.

\subsection{Read to Write}

English paragraphs or articles are supposed to follow two basic criteria: one is consistency, which highlights the theme, and the details are closely related to theme; the other is coherence, which means a logical structure. The use of transitional words can be seen as one of the essential means to reach the coherence of paragraphs or articles, which needs the same attention in English reading. To reach a full understanding of an English passage, it is necessary for readers to analyse the writing structure of the passage, which will facilitate reading by providing some logical structure. The development of each English article or paragraph always follows a certain pattern, which will possibly be used in future writing.

Moreover, cultivating a sensitive mind towards typical English passages will help readers accumulate some reading techniques for future use. One of the techniques is to underline some key words or expressions, especially transitions, which appear in the passage, and summarize their functions in the passage. If possible, draw a mind map with the help of the transitional words and phrases. By analysing the logical structure, readers can have a further understanding of what they read, and by summarizing they may find a way to write.

\subsection{Apply in Writing}

Many researchers have noticed that some Chinese students often do not pay enough attention to the use of transitional words in English writing. And at the same time some students can't use them properly or overuse them. Therefore, their writings always seem confusing or weak in logical organization. As a matter of fact, what they should do first is not to memorize the vocabulary of transitional words and phrase, but to have a better understanding of how they function in paragraphs and passages.

First, sufficient input is needed. Single transitional words and phrases are far from enough. The context may help the students learn in authentic language learning environment to learn transitions and how they are applied. In the teaching of English writing, teachers should guide students to study the structure of the text, especially the wise using of transitional words, not just focusing on accurate and appropriate English statements. In order to write an article with coherent meaning and logical language order, the students should be encouraged to have an inquiring mind, keep on accumulating elegant ways of organizing their ideas.

Second, it is also necessary to have a systematic summary of the definition, features and functions of English transitional devices and their practical application in English writing. Therefore, the students may have certain guidelines to follow when writing.

Third, accumulating helps improve the diversity of language. If too many simple sentences were used in writing, it would become a day-to-day account. And too frequent use of a few transitions will make the language lose diversity. To avoid this problem, different transitional words should be encouraged.

Finally, application is the most important process in improving the ability of skilfully using the transitions. One cannot find the perfect way during this process, but keep looking for a more suitable way of expression. Although the use of the transitional words is not the only means of making writing logical and coherent, it is an essential method in coherence improving.

\section{CONCLUSION}

Based on the difference between the Chinese and English, the application of transitional devices in English writing should be taken into consideration. On the one hand, English is a language placing great emphasis on both structure and logic. However, Chinese tends to focus more on meaning. On the other hand, English mainly depends on some transitional words and phrases to organize the different sections of a paragraph or article so as to form a coherent and logical structure.

According to different functions, transitional words and phrases are briefly divided into two categories, meaning and logical structure, according to which different transitions can be employed in different situation. Thus we can follow the guideline in writing.

As for the application of transitional devices, writing should not be isolated from reading, which provides authentic context for readers to further understand the transitional words and phrases.

Four steps are mentioned in English writing teaching. It may be beneficial for students to get sufficient language input from reading, after which systematic summary of transitional devices will give them insight into the guidelines of using them. What's more, diversity of language should not be ignored so accumulation is necessary. Finally, skilful application of transitional devices may come from day-to-day practice. 


\section{REFERENCES}

[1] Blakemore, D. Semantic Constraints on Relevance [M]. Blackwell: Oxford Press.1987 https://doi.org/10.1016/0024-3841(88)90024-1

[2] Chalker, S. Collins Cobulid English Guides: 9. Linking Words. [M]. Beijing: Foreign Language Press. 2001

[3] Brown, G. and Yule, G. Discourse Analysis [M]. Cambridge: Cambridge University Press. 1987

[4] Freebody, P. and Anderson, R. C. Effects of Vocabulary Difficulty, Text Cohesion, and Schema Availability on Reading Comprehension [J]. Reading Research Quarterly.1981

[5] Iten, C and Givon, T. Although revisited [J]. UCL Working Papers in Linguistics. 2000

[6] Knott, A. and Dale, R. Using Linguistic Phenomena to Motivate a set of Coherence Relations [J]. Discourse Processes 18: 35-62.1994

[7] Lisa S. L. Kwan; Melor Md Yunus. Cohesive Errors in Writing among ESL Pre-Service Teachers[J] . English Language Teaching. 2014 (11) DOI: $10.5539 /$ elt.v7n11p130

[8] Abdulkerim Karadeniz. Cohesion and Coherence in Written Texts of Students of Faculty of Education $[\mathrm{J}]$. Journal of Education and Training Studies.2017(2) DOI: 10.11114/jets.v5i2.1998

[9] Afnan Bahaziq. Cohesive Devices in Written Discourse: A Discourse Analysis of a Student's Essay Writing[J]. English Language Teaching. 2016 (7) DOI: 10.5539/elt.v9n7p112

[10]Lexical Cohesion: An Issue only in the Foreign Language?[J] . Huseyin Kafes. English Language Teaching . 2012 (3) DOI: 10.5539/elt.v5n3p83

[11]Fatemeh Mirzapour,Maryam Ahmadi. Study on Lexical Cohesion in English and Persian Research Articles (A Comparative Study) [J]. English Language Teaching. 2011 (4) DOI: 10.5539/elt.v4n4p245

[12] Meihua Liu,George Braine. Cohesive features in argumentative writing produced by Chinese undergraduates[J]. System. 2005 (4)

[13] Somchai Watcharapunyawong, Siriluck Usaha. Thai EFL Students' Writing Errors in Different Text Types: The Interference of the First Language[J]. English Language Teaching. 2013 (1) DOI: $10.5539 /$ elt.v6n1p67

[14] Enas Abdelwahab Eltom RahmtAllah EFL Students' Coherence Skill in Writing: A Case
Study of Third Year Students of Bachelors in English Language [J] English Language Teaching, 2020 DOI: 10.5539/elt.v13n8p120

[15] Chen Qingxin. Cohesion and Coherence in College English Writing Teaching. [J] Advances in Higher Education Volume 3, Issue 2, 2019 DOI: 10.18686/ahe.v3i2.1405

[16] Shi Jian, Shuai Peitian. English Writing from Sentence to Paragraph and to Theme. Foreign Language Teaching and Research Press. 2010 